\title{
Development of a Method to Detect Three Monohydroxylated Polycyclic Aromatic Hydrocarbons in Human Urine by Liquid Chromatographic Tandem Mass Spectrometry
}

\author{
Xiaotao Zhang, Hongwei Hou, Wei Xiong, and Qingyuan Hu \\ China National Tobacco Quality Supervision \& Test Center, No. 2 Fengyang Street, Zhengzhou, Henan 450001, China \\ Correspondence should be addressed to Hongwei Hou; qsfctc@163.com and Qingyuan Hu; huqy1965@163.com
}

Received 23 January 2015; Accepted 17 March 2015

Academic Editor: Jesus Simal-Gandara

Copyright (c) 2015 Xiaotao Zhang et al. This is an open access article distributed under the Creative Commons Attribution License, which permits unrestricted use, distribution, and reproduction in any medium, provided the original work is properly cited.

\begin{abstract}
A liquid chromatographic tandem mass spectrometry method (LC-MS/MS) for the simultaneous determination of 1hydroxypyrene (1-OHP), 3-hydroxybenzo[a]pyrene (3-OHBaP), and 3-hydroxybenz[a] anthracene (3-OHBaA) in human urine has been developed. With the exception of $3-\mathrm{OHBaP}$ at a low spiking level, the average recoveries were greater than $80 \%$. The method has good accuracy (72.1-107.7\%) and reproducibility (1.8-11.4\%) and was successfully used to study the uptake of pyrene, benzo[a]pyrene, and benzo[a]anthracene from cigarette smoke. The results indicated that urinary 1-OHP concentration in the smoking group $(66.58 \pm 70.91 \mathrm{ng} / \mathrm{g}$ creatinine) was higher than that observed in the nonsmoking group (58.16 $\pm 49.48 \mathrm{ng} / \mathrm{g}$ creatinine). Urinary 3 -OHBaA concentrations in nonsmokers and smokers with $8 \mathrm{mg}$ and $10 \mathrm{mg}$ tar cigarettes were $10.98 \pm$ $4.39 \mathrm{ng} / \mathrm{g}$ creatinine, $11.01 \pm 13.30 \mathrm{ng} / \mathrm{g}$ creatinine, and $9.17 \pm 12.89 \mathrm{ng} / \mathrm{g}$ creatinine, respectively. Urinary 3-OHBaP concentrations in nonsmokers and smokers with $8 \mathrm{mg}$ and $13 \mathrm{mg}$ tar cigarettes were $1.30 \pm 0.20 \mathrm{ng} / \mathrm{g}$ creatinine, $2.83 \pm 1.78 \mathrm{ng} / \mathrm{g}$ creatinine, and $6.00 \pm 4.44 \mathrm{ng} / \mathrm{g}$ creatinine, respectively. Urinary 1-OHP levels exhibited a significant correlation with BaP yield in cigarette smoke under the Canadian intense smoking condition $\left(y=3.5563 x+30.171, R^{2}=0.9916, n=227\right)$.
\end{abstract}

\section{Introduction}

Polycyclic aromatic hydrocarbons (PAHs) mainly from incomplete combustion of organic matter are an important class of environmental contaminants, which is found in food [1-3], feed [4, 5], drinking water [6], and so forth. PAHs are also present in cigarette smoke. Pyrene, benzo[a]pyrene, and benz [a] anthracene are thought to be the most common PAHs in cigarette smoke. Benzo(a)pyrene, benz(a)anthracene, and pyrene have been classified as category 1 , category $2 \mathrm{~B}$, and category 3 carcinogens, respectively, by IARC [7]. In addition, they have been identified as priority environment pollutants by the U.S. Environmental Protection Agency. PAHs in the environment field have been the focus of attention; there are a number of related researches to be reported. For example, Professor Simal-Gandara established the methods to measure PAHs in various foods by the optimization of pretreatment method, such as solid-phase extraction [6] or ultrasoundassisted solvent extraction [8], investigated their potential sources [5, 9], and studied the removal method of PAHs in fish oils [2] and organic solvents [10]. People may be exposed to pyrene, benzo[a]pyrene, and benz[a]anthracene through inhalation, ingestion, or skin absorption. In vivo, pyrene, benzo[a]pyrene, and benz[a]anthracene are metabolised to 1-hydroxypyrene (1-OHP), 3-hydroxybenzo[a]pyrene (3$\mathrm{OHBaP})$, and 3-hydroxybenz[a] anthracene (3-OHBaA), respectively, which are excreted in urine. Those three urinary monohydroxylated PAHs (OH-PAHs) are commonly used as biomarkers to monitor human PAHs exposure and assess the environmental and human health risks $[11,12]$.

High performance liquid chromatography (HPLC) with fluorescence detection has been widely used in the determination of urinary OH-PAHs, particularly 1-OHP [13-17]. This method has many advantages including that the instruments are available in most laboratories, the fluorescence detection is highly sensitive, and good specificity for PAH metabolites can be achieved. However, these methods often require fairly large urine specimens $(10 \mathrm{~mL}$ or more) and long HPLC run 
times, and most do not employ an internal standard, the use of which is generally expected to result in better precision and accuracy [18-20].

Gas chromatograph (GC) and gas chromatography-mass spectrometer (GC-MS) methods have also been used to detect OHPAHs [21-23]. Recently, high resolution GC-MS methods have been used for the simultaneous determination of several PAH metabolites, demonstrating high sensitivity and specificity $[24,25]$. However, time-consuming sample pretreatment and derivatization steps are required prior to GC-MS analysis.

Owing to the fact that LC tandem mass spectrometry (LC-MS/MS) can be used to quantify a wide range of substances in complex biological matrixes at low levels with high specificity and short chromatographic run times, LC timeof-flight MS with electrospray ionization (ESI) [26] and LCMS/MS with ESI [27] have been used to detect 1-OHP, and a LC-MS method utilizing a single quadrupole instrument with ESI has been used to determine phenolic PAH metabolites in vitro [28]. Recently, certain OHPAH metabolites have been selectively quantified in human urine using LC-MS/MS [2932]. However, those methods focused only on 1-OHP or 3$\mathrm{OHBaP}$. To date, simultaneous measurements of urinary 1OHP, 3-OHBaP, and 3-OHBaA using LC-MS/MS are sparse.

In this study, we describe a LC-MS/MS method for simultaneous determination of urinary 1-OHP, 3-OHBaP, and 3$\mathrm{OHBaA}$. The proposed method has good precision and accuracy, very high sensitivity, an extraction procedure suitable for processing large batches of samples, and a relatively short chromatographic run time (12 min). This method was successfully applied to determine 1-OHP, 3-OHBaP, and 3$\mathrm{OHBaA}$ levels in urine samples obtained from 81 smokers and 58 nonsmokers.

\section{Materials and Methods}

2.1. Chemicals and Reagents. 1-OHP was obtained from Dr. Ehrenstorfer GmbH (Augsburg, Germany, purity 98.5\%). 3$\mathrm{OHBaP}$ was purchased from the Institute for Reference Materials and Measurements (Belgium, European Commission, purity 99.4\%). 3-OHBaA was purchased from MRIGlobal (Kansas City, Missouri, purity $>97 \%$ ) and the $\mathrm{D}_{9}-1-\mathrm{OHP}$ internal standard (chemical purity $97 \%$, isotopic purity $99 \%$ ) was purchased from Toronto Research Chemicals Inc. (Toronto, Canada). $\beta$-Glucuronidase-arylsulfatase $(30 \mathrm{U} / \mathrm{mL} \beta$ glucuronidase, $60 \mathrm{U} / \mathrm{mL}$ sulfatase) was purchased from Merck (Darmstadt, Germany). HPLC-grade acetonitrile was obtained from TEDIA Company Inc. (Ohio, USA).

2.2. Standard Solutions of PAH Metabolites. Approximately $2 \mu \mathrm{g} / \mathrm{mL}$ of 1-OHP and 3-OHBaP was dissolved/diluted in acetonitrile to obtain separate stock solutions of each compound. 3-OHBaA was diluted in the same way to a concentration of approximately $1 \mu \mathrm{g} / \mathrm{mL}$. The $\mathrm{D}_{9}-1-\mathrm{OHP}$ (internal standard) solution was diluted in acetonitrile to concentrations of $50 \mu \mathrm{g} / \mathrm{mL}$ as a stock solution and $100 \mathrm{ng} / \mathrm{mL}$ as a working solution. Aliquots of the three standard stock solutions were mixed, and $100 \mu \mathrm{L}$ of internal standard solution $(100 \mathrm{ng} / \mathrm{mL})$ was added. This solution was further diluted with acetonitrile to obtain a series of standard solutions ranging within 0.50-25.00 ng/mL for 1-OHP, $0.10-5.00 \mathrm{ng} / \mathrm{mL}$ for 3-OHBaP, and $0.25-12.50 \mathrm{ng} / \mathrm{mL}$ for 3-OHBaA. All stock and standard solutions were stored at $-80^{\circ} \mathrm{C}$.

2.3. Assay Development and Validation. The method was validated for specificity, matrix effects, precision, accuracy, linearity, sensitivity, recovery, and stability according to US Food and Drug Administration (FDA) guidelines for the validation of bioanalytical methods [33]. The specificity of this method was determined using three individual human blank urine samples. The matrix effects on the ionization efficiency of each analyte were evaluated by comparing the peak response of the analyte dissolved in pooled blank sample extract (i.e., the final solution obtained from the pooled blank urine sample after extraction and reconstitution) with that of the analyte diluted to the same concentration in the mobile phase (as a reference). The calibration curves were constructed via linear regression using a weighing factor of $1 / C$, where $C$ is the concentration of each calibration standard. Correlation coefficients ( $r$ values) were required to be greater than or equal to 0.99 . The limits of quantification (LOQs) were calculated using the background noise level estimated from the peak-to-peak baseline near the analyte peaks. The precision and accuracy of the method were assessed by intraand interday validation experiments. The intra- and interday accuracy and precision were obtained by determining the concentrations of $1-\mathrm{OHP}, 3-\mathrm{OHBaP}$, and $3-\mathrm{OHBaA}$ in five replicates of pooled blank urine samples for three separate batches. Precision was expressed as the relative standard deviation (RSD). Accuracy was expressed in terms of bias as the percent deviation of the mean determined concentration against the spiked concentration. The recoveries of 1-OHP, 3$\mathrm{OHBaP}$, and 3-OHBaA were determined by comparing the analyte responses obtained from pooled blank urine samples with those obtained from prepared urine samples that were spiked with equivalent analyte concentrations. Freeze-thaw stability was assessed by exposing samples with moderate concentrations to three freeze-thaw cycles. In each cycle, the samples were removed from the freezer, thawed (unassisted) to room temperature, kept at room temperature for $2 \mathrm{~h}$, and refrozen at $-80^{\circ} \mathrm{C}$ for $8 \mathrm{~h}$.

2.4. Instruments and Conditions. Samples were analyzed by an Agilent 1200 rapid-resolution liquid chromatography instrument (autosampler G1367D, binary gradient pump G1312B, column oven G1316B; Agilent Technologies, Palo Alto, CA) on a Phenomenex Synergi Hydro-RP column $(2.0 \times 100 \mathrm{~mm}$, $2.5 \mu \mathrm{m}$ particle size, California, USA) and equilibrated with $40 \%$ solvent A (water) and $60 \%$ solvent B (acetonitrile) at $380 \mu \mathrm{L} / \mathrm{min}$. The gradient conditions were $0-2.5 \mathrm{~min}, 40 \% \mathrm{~A}$; 2.5-3.5 min, 10\% A; 3.5-8 min, 10\% A; 8-8.1 min, 90\% A; 8.1$11 \mathrm{~min}, 90 \% \mathrm{~A} ; 11-11.1 \mathrm{~min}, 40 \% \mathrm{~A} ; 11.1-12 \mathrm{~min}, 40 \%$ A.

An API 5500 triple quadruple mass spectrometer (Applied Biosystems, Foster City, CA) was used in APCI positive ionization mode. Mass detection conditions were as follows: ion spray voltage, $5500 \mathrm{~V}$; ion source temperature, $400^{\circ} \mathrm{C}$; 
nebulizer gas, nitrogen, 60 psi; curtain gas, nitrogen, 25 psi; collision gas (CID), nitrogen, setting 8 . The MRM transitions of $m / z 219.2 \rightarrow 189.1, m / z 269.1 \rightarrow 252.1, m / z 245.1 \rightarrow 215.1$, and $\mathrm{m} / z 228.2 \rightarrow 198.1$ were optimized for the quantitation of $1-$ OHP, 3-OHBaP, 3-OHBaA, and IS, respectively; $m / z 219.2 \rightarrow$ $201.1, \mathrm{~m} / z 269.1 \rightarrow 239.1$, and $\mathrm{m} / z 245.1 \rightarrow 226.2$ were used as confirmation ions for 1-OHP, 3-OHBaP, and 3-OHBaA, respectively.

2.5. Urine Sample Collection and Preparation. 81 Chinese smokers and 58 Chinese nonsmokers from the city of Zhengzhou were enrolled in the study. For each subject, data regarding smoking habits, age, and job description were collected using a questionnaire administered by trained interviewers. The clinical portion of this study was conducted by the Institute of Clinical Pharmacology of Zhengzhou University in 2010. The study was approved by the Institutional Review Board for Zhengzhou University, China. All participants in the study gave written consent. The ages and occupations of the nonsmokers matched those of the smokers (Table 1). The study was conducted during three separate periods, each including two consecutive days. Every smoker smoked an appointed brand of Chinese Virginia cigarettes and switched to a cigarette of a different tar yield in the next experimental period. All 81 smokers smoked three brands of cigarettes with different tar yields $(8,10$, and $13 \mathrm{mg} /$ cigarette $)$ over the three nonconsecutive periods. Urine samples were collected from each smoker every $24 \mathrm{~h}$ on three nonconsecutive days and stored at $-80^{\circ} \mathrm{C}$ until analysis.

Urine $(10 \mathrm{~mL})$ from each subject was transferred to a conical flask $(25 \mathrm{~mL})$. The $\mathrm{pH}$ of the solution was adjusted to 5.0 with $0.2 \mathrm{M} \mathrm{HCl}$, and $2.5 \mathrm{~mL}$ of $0.5 \mathrm{M}$ acetate buffer ( $\mathrm{pH} 5.0$ ) and $100 \mu \mathrm{L}$ of internal standard solution $(100 \mathrm{ng} / \mathrm{mL})$ were added. After the addition of $30 \mu \mathrm{L} \beta$-glucuronidase/arylsulfatase, the conical flask was covered with aluminum foil and placed in a shaker bath overnight at $37^{\circ} \mathrm{C}$ to completely hydrolyze the conjugated $\mathrm{PAH}$ metabolites.

The optimization of the experimental parameters associated with the retention and elution of PAH metabolites (from the solid-phase cartridge) resulted in the following procedures. Aqueous metabolite solutions were processed through a Supelco-ENVI C-18 cartridge $(500 \mathrm{mg}, 3 \mathrm{~mL})$ that was previously conditioned with $5 \mathrm{~mL}$ methanol and $5 \mathrm{~mL}$ water. All solutions were injected onto the cartridge with the aid of a $10 \mathrm{~mL}$ syringe (attached to the cartridge). The cartridge was sequentially rinsed with $10 \mathrm{~mL}$ water and $10 \mathrm{~mL}$ of $30 \%$ methanol in water. After the cartridge was dried completely, the trapped metabolites were eluted with $4 \mathrm{~mL}$ of methanol. The elution was evaporated to dryness under nitrogen gas and redissolved in $150 \mu \mathrm{L}$ of methanol. The solution was filtered through a $0.22 \mu \mathrm{m}$ filter and then stored at $-20^{\circ} \mathrm{C}$ until LCMS/MS analysis.

2.6. Determination of Urinary Cotinine and Creatinine. Urinary cotinine levels were analyzed according to a previously published LC-MS/MS method [34]. Briefly, $250 \mu \mathrm{L}$ urine samples were pipetted into separate polypropylene tubes, and $25 \mu \mathrm{L}$ of the internal standard solution $(10 \mu \mathrm{g} / \mathrm{mL})$ and $725 \mu \mathrm{L}$
TABLE 1: Demographics of subjects.

\begin{tabular}{lccc}
\hline & Gender & Age (years) & $\begin{array}{c}\text { Smoking habits } \\
\text { (number) }\end{array}$ \\
\hline $\begin{array}{l}\text { Nonsmokers } \\
(n=58)\end{array}$ & Man & $22.34 \pm 1.46$ & \\
$\begin{array}{l}\text { Smokers } \\
(n=81)\end{array}$ & $\begin{array}{c}78 \text { men, } \\
\text { 3 women }\end{array}$ & $22.95 \pm 2.10$ & $9.50 \pm 5.30$ \\
\hline
\end{tabular}

The results were expressed as mean \pm standard deviation.

of water were added. The mixed samples were vortex-mixed for $2 \mathrm{~min}$. After centrifugation for $15 \mathrm{~min}$, the supernatants were filtered through a $0.22 \mu \mathrm{m}$ syringe filter. $5 \mu \mathrm{L}$ of the filtrates was then introduced into the LC-MS/MS system.

Urinary creatinine levels were analyzed according to a previously published LC-MS/MS method [35]. Briefly, $10 \mu \mathrm{L}$ of formic acid was added to a $1 \mathrm{~mL}$ aliquot of human urine sample, stirred, and centrifuged at $10000 \mathrm{rpm}$ for $10 \mathrm{~min}$. The mixture was filtered through a $0.22 \mu \mathrm{m}$ polyethersulfone membrane. $5 \mu \mathrm{L}$ of urine aliquot was transferred to an amber volumetric flask and brought to a total volume of $10 \mathrm{~mL}$ with water after being spiked with $100 \mu \mathrm{L}$ of creatinine- $\mathrm{d}_{3}$ internal standard solution $(1 \mu \mathrm{g} / \mathrm{mL}) .5 \mu \mathrm{L}$ aliquot was then injected on-column for LC-MS/MS analysis.

\subsection{Determination of BaP Yields in Mainstream Cigarette} Smoke. BaP yields under different machine smoking regimes using the appointed brands of cigarettes with different tar yields $(8,10$, and $13 \mathrm{mg} /$ cigarette) were analyzed according to the reported method [36]. Cigarette smoking was carried out with a SM450 linear smoking machine (Cerulean, UK) according to ISO 3308:2000 [37] and the Canadian intense machine smoking regime. The Canadian intense smoking regime was as follows. Each cigarette was smoked at 1 puff/ $30 \mathrm{~s}$; each puff had a duration of $2 \mathrm{~s}$ and a volume of $55 \mathrm{~mL}$ with $100 \%$ filter ventilation blocking. Typically, five cigarettes were smoked per port for the ISO regime, and three cigarettes were smoked per port for the Canadian intense regime. All samples were smoked to a butt mark of $3 \mathrm{~mm}$ past the tipping paper overwrap.

\section{Results}

3.1. Method Validation. Calibration standard solutions were prepared by diluting standard solutions to the appropriate concentrations with pooled blank human urine while a $100 \mu \mathrm{L}$ internal standard solution was added. The calibration standard solutions were also processed with SPE using the same procedure applied to the real urine samples. The concentrations of the calibration standard solutions (in urine) were $0.008,0.015,0.030,0.076,0.152$, and $0.379 \mathrm{ng} / \mathrm{mL}$ for $1-$ OHP; $0.002,0.003,0.006,0.015,0.030$, and $0.076 \mathrm{ng} / \mathrm{mL}$ for 3 -OHBaP; and 0.004, 0.008, 0.015, 0.038, 0.076, and $0.19 \mathrm{ng} /$ $\mathrm{mL}$ for $3-\mathrm{OHBaA}$. All urine samples were stored at $-80^{\circ} \mathrm{C}$ until analysis. Each analyte exhibited good linearity with a coefficient of determination $(r)$ exceeding 0.99 . Data analysis resulted in the following representative regression equations: $Y=0.454 X+2.06$ for 1 -OHP, $Y=0.215 X+0.236$ for 
TABLE 2: Recovery and precision data for 1-OHP, 3-OHBaP, and 3-OHBaA.

\begin{tabular}{|c|c|c|c|c|c|}
\hline & $\begin{array}{l}\text { Spiked } \\
\mathrm{ng} / \mathrm{mL}\end{array}$ & $\begin{array}{l}\text { Conc. } \\
\mathrm{ng} / \mathrm{mL}\end{array}$ & $\begin{array}{l}\text { Recovery } \\
n=6,(\%)\end{array}$ & $\begin{array}{c}\text { Intraday precision } \\
n=6,(\%)\end{array}$ & $\begin{array}{c}\text { Interday precision } \\
n=6,(\%)\end{array}$ \\
\hline \multirow{3}{*}{ 1-OHP } & 0.015 & 0.016 & 106.7 & 6.5 & 11.4 \\
\hline & 0.076 & 0.080 & 105.6 & 5.1 & 4 \\
\hline & 0.23 & 0.24 & 104.3 & 5.5 & 4 \\
\hline \multirow{3}{*}{ 3-OHBaP } & 0.003 & 0.002 & 72.1 & 8.8 & 5.9 \\
\hline & 0.015 & 0.012 & 80.2 & 4.5 & 7.3 \\
\hline & 0.045 & 0.036 & 80.7 & 5.2 & 6 \\
\hline \multirow{3}{*}{ 3-OHBaA } & 0.008 & 0.007 & 87.5 & 6.1 & 8.4 \\
\hline & 0.038 & 0.036 & 94.7 & 5.8 & 6.7 \\
\hline & 0.114 & 0.1135 & 99.6 & 3.9 & 1.8 \\
\hline
\end{tabular}

3-OHBaP, and $Y=1.23 X-0.013$ for 3-OHBaA, where $Y$ indicates the analyte/IS ratio and $X$ indicates the urine concentration. The slopes of these regression equations were reproducible for calibration curves determined on three separate occasions (over 3 days). Under optimized conditions, the LOQs (determined when the RSD for precision and the bias for accuracy were both less than 20\%, and the signal/noise ratios were approximately 10) were $0.003 \mathrm{ng} / \mathrm{mL}$ for $1-\mathrm{OHP}$, $0.002 \mathrm{ng} / \mathrm{mL}$ for $3-\mathrm{OHBaP}$, and $0.004 \mathrm{ng} / \mathrm{mL}$ for $3-\mathrm{OHBaA}$.

Table 2 demonstrates that the method was accurate, precise, and reproducible for 1-OHP, 3-OHBaP, and 3-OHBaA detection over the tested concentration ranges. The extraction recoveries and the RSD values determined for the analytes (in urine, $n=6$ ) are also shown in Table 2. At low spiking concentration, $3-\mathrm{OHBaP}$ recoveries were lower than $80 \%$, whereas the recoveries of the other analytes were always greater than $80 \%$ at low, middle, and high spiking levels. All analytes were found to be stable in urine when stored at $-80^{\circ} \mathrm{C}$ for 30 days. No measurable loss of the analytes was observed after three freeze/thaw cycles.

To determine the effects of endogenous interferences, the specificity was assessed by comparing the chromatograms of analyte-free human urine samples with those of the spiked urine samples. Under the described chromatographic conditions, the retention times of 1-OHP, 3-OHBaP, 3-OHBaA, and IS were $3.44,5.94,4.31$, and $3.29 \mathrm{~min}$, respectively. Representative chromatograms from a nonsmoker and smoker are shown in Figures 1 and 2, respectively. No interfering peaks were observed in the chromatograms of the blank urine samples extracted from the nonsmoker. Matrix interference, caused by endogenous materials in the urine samples, was evaluated by comparing the peak areas of spiked standards with those of the standards of pooled blank urine concentrations. The ratios obtained were within the acceptable limits. No significant ion suppressions or enhancements were observed at the expected retention times of the targeted ions.

3.2. Urinary Excretion of 1-OHP, 3-OHBaP, and 3-OHBaA. The proposed method was successfully used to analyze 58 urine samples from 58 nonsmokers and 243 urine samples from 81 smokers (smokers smoked $8 \mathrm{mg}, 10 \mathrm{mg}$, and $13 \mathrm{mg}$ tar cigarettes in three different weeks, and urine samples were then collected every $24 \mathrm{~h}$ ); the results are shown in Figure 3.
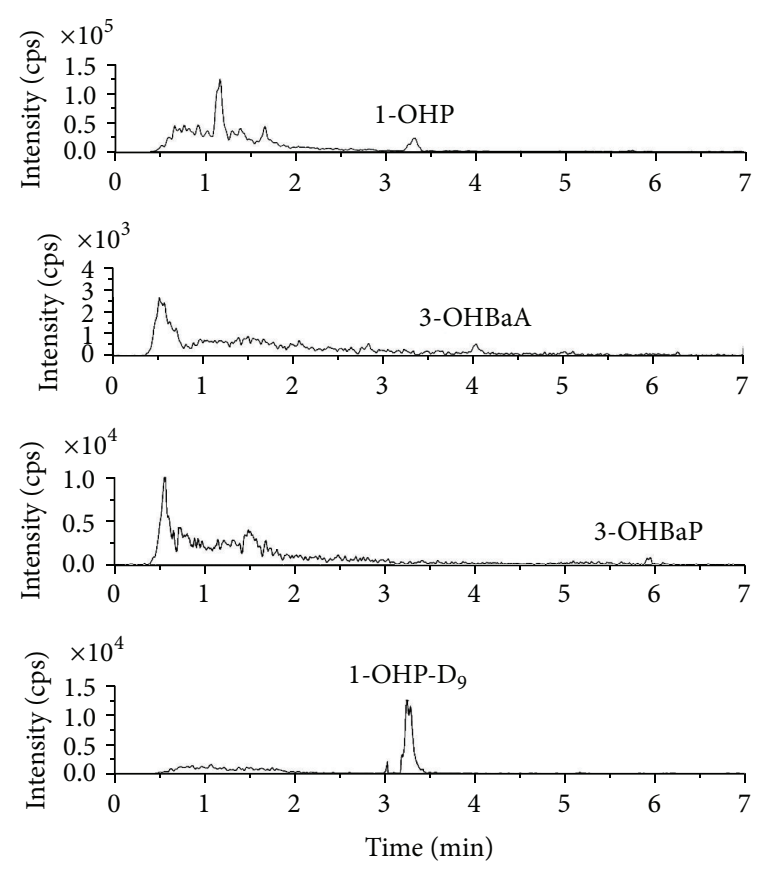

FIGURE 1: Representative chromatogram from a nonsmoker.

After removing the outliers and the values lower than the LOQs from each group, the final results were summarized as geometric means (GMs) and geometric standard deviations (GSDs) (Table 3). With the exceptions of urinary 3-OHBaA in smokers with $13 \mathrm{mg}$ tar cigarettes and 3-OHBaP in smokers with $10 \mathrm{mg}$ tar cigarettes, urinary 1-OHP, 3-OHBaA, and 3$\mathrm{OHBaP}$ levels in smokers were higher than those in nonsmokers.

Because spot urine sampling may not provide a valid overview of the entire toxicant exposure profile [38] and is easily influenced by other factors (e.g., diet), urinary 1$\mathrm{OHP}, 3-\mathrm{OHBaA}$, and 3-OHBaP concentrations were adjusted by creatinine excreted in urine at a relatively constant rate through glomerular filtration. The results after the creatinine correction are summarized in Table 4. Urinary 1-OHP and 3-OHBaP levels increased with tar content, while 3-OHBaA levels did not. Significant differences were observed in 

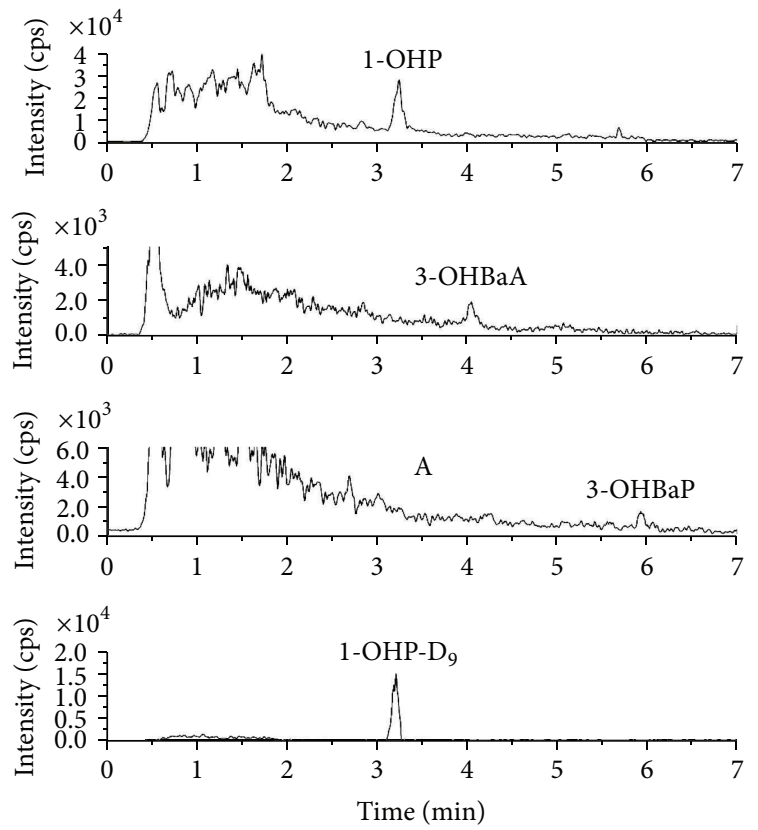

FIGURE 2: Representative chromatogram from a smoker.

the urinary 1-OHP levels between smokers with $8 \mathrm{mg}$ tar cigarettes and $10 \mathrm{mg}$ tar cigarettes $(P<0.01)$ and between smokers with $10 \mathrm{mg}$ tar cigarettes and $13 \mathrm{mg}$ tar cigarettes $(P<$ $0.05)$. However, the differences in urinary $3-\mathrm{OHBaA}$ and $3-$ $\mathrm{OHBaP}$ between different groups of smokers were not significant $(P>0.05)$. The correlation between 1-OHP in $24 \mathrm{~h}$ urine and the nicotine metabolite cotinine, which is a recognized biomarker for tobacco exposure, was also studied (Figure 4). The correlation between urinary 1-OHP and cotinine was weak $\left(y=1.7932 x+571.31, R^{2}=0.0256\right)$.

\section{Discussion}

Pyrene, benzo[a]pyrene, and benz[a]anthracene are ubiquitously present in the environment and cigarette smoke and are associated with a variety of adverse health effects. In mainstream cigarette smoke, the levels of benzo[a]pyrene and benz[a] anthracene ranged from 8.5 to $11.6 \mathrm{ng} / \mathrm{cig}$ and 20 to $70 \mathrm{ng} / \mathrm{cig}$ [39], respectively. OH-PAHs have been employed as biomarkers for the human exposure assessment of PAHs [32]. In previous studies $[30,31,40]$, only the single analyte determination of 1-OHP or 3-OHBaP was carried out. Here, we developed a new LC-APCI-MS/MS method to simultaneously analyze urinary $1-\mathrm{OHP}, 3-\mathrm{OHBaP}$, and $3-\mathrm{OHBaA}$. The proposed method has good precision and accuracy, very high sensitivity, an extraction procedure suitable for processing large batches of samples, and a relatively short chromatographic run time (12 min).

Urinary 1-OHP concentrations in nonsmokers $(58.16 \mathrm{ng} / \mathrm{g}$ creatinine) and smokers (66.85 ng/g creatinine) in this study were lower than those reported in France by Lafontaine et al. (84.88 ng/g creatinine and $277.6 \mathrm{ng} / \mathrm{g}$ creatinine) [41], which may result from differences in subjects due to their different
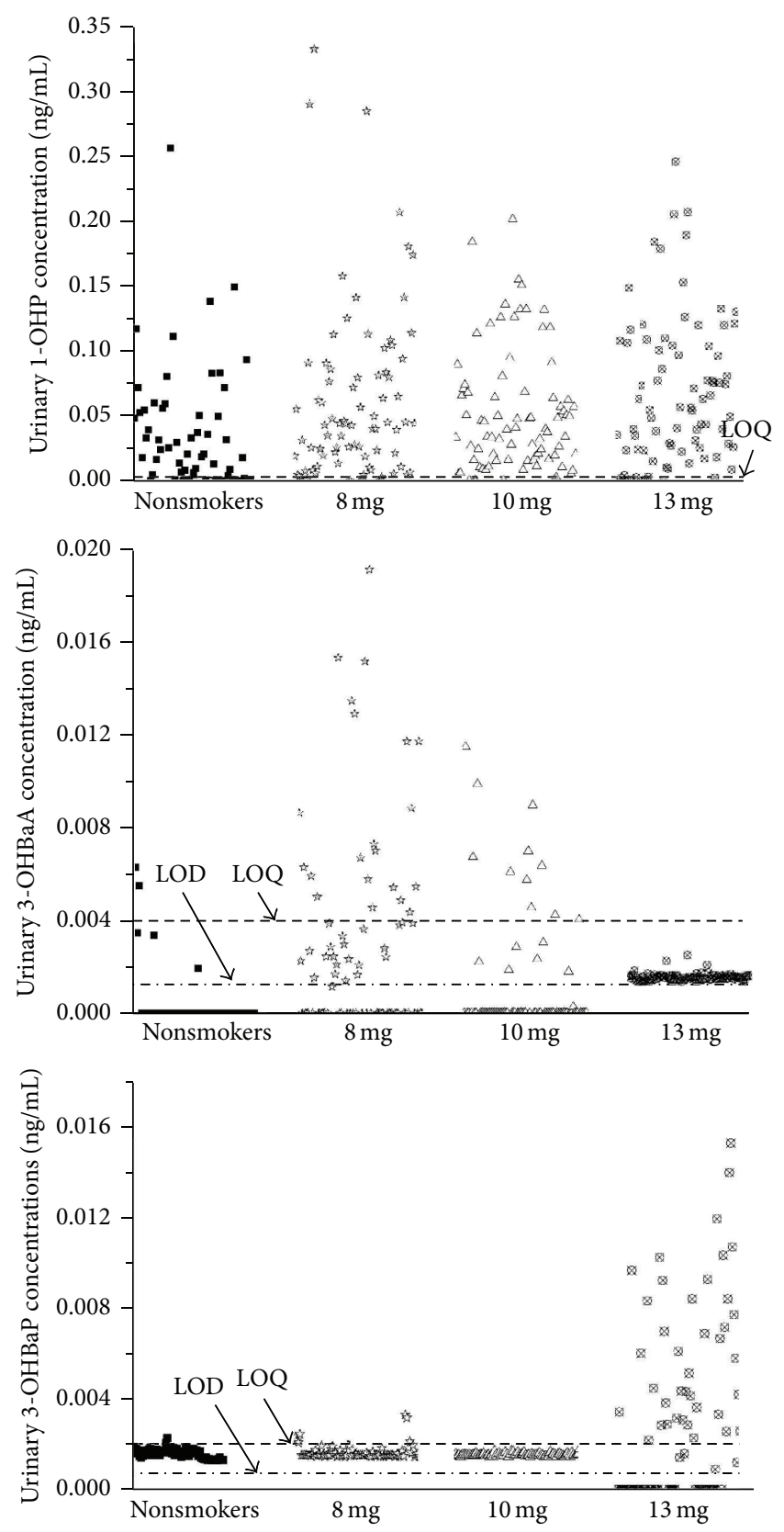

FIgURE 3: Urinary 1-OHP, 3-OHBaA, and 3-OHBaP concentrations from nonsmokers and smokers.

environments and the type and number of cigarettes used. In Lafontaine's study, blended cigarettes were used, and smokers smoked 15-30 cigarettes per day, which was two times as many as ours. In addition, daily exposure to the sum of benzo[a]pyrene, benz[a]anthracene, chrysene, and benzo[b]fluoranthene was higher in France (estimated at $1.48 \mathrm{ng} / \mathrm{kg} \mathrm{bw} /$ day in adults and $2.26 \mathrm{ng} / \mathrm{kg}$ bw/day in children) [42]. Urinary 3-OHBaA levels in nonsmokers and smokers were lower than those for people in the US over 20 years of age [43]. In the studies of Fan et al. [29] and Lafontaine et al. [41], the average concentrations of 3$\mathrm{OHBaP}$ were $14.23 \mathrm{ng} / \mathrm{g}$ creatinine and $33.2 \mathrm{ng} / \mathrm{g}$ creatinine, 
TABLE 3: Urinary 1-OHP, 3-OHBaP, and 3-OHBaA concentration after removing abnormal value.

\begin{tabular}{|c|c|c|c|c|c|}
\hline \multirow{2}{*}{ Analyte } & \multirow{2}{*}{ Nonsmokers } & \multicolumn{4}{|c|}{ Smokers } \\
\hline & & $8 \mathrm{mg}$ & $10 \mathrm{mg}$ & $13 \mathrm{mg}$ & Total \\
\hline $\begin{array}{l}\text { 1-OHP } \\
\text { (ng/mL) }\end{array}$ & $0.047 \pm 0.048(n=46)$ & $0.057 \pm 0.058(n=74)$ & $0.047 \pm 0.040(n=79)$ & $0.062 \pm 0.048(n=74)$ & $0.055 \pm 0.050(n=227)$ \\
\hline $\begin{array}{l}3-\mathrm{OHBaA} \\
(\mathrm{ng} / \mathrm{mL})\end{array}$ & $0.006 \pm 0.0006(n=2)$ & $0.008 \pm 0.004(n=23)$ & $0.009 \pm 0.009(n=13)$ & - & $0.008 \pm 0.006(n=36)$ \\
\hline $\begin{array}{l}\text { 3-OHBaP } \\
(\mathrm{ng} / \mathrm{mL})\end{array}$ & $0.002 \pm 0.0002(n=2)$ & $0.0024 \pm 0.0005(n=9)$ & - & $0.006 \pm 0.003(n=39)$ & $0.005 \pm 0.003(n=48)$ \\
\hline
\end{tabular}

The results were expressed as mean \pm standard deviation.

TABLE 4: Urinary 1-OHP, 3-OHBaP, and 3-OHBaA concentration after creatinine correction.

\begin{tabular}{|c|c|c|c|c|c|}
\hline \multirow{2}{*}{ Analyte } & \multirow{2}{*}{ Nonsmokers } & \multicolumn{4}{|c|}{ Smokers } \\
\hline & & $8 \mathrm{mg}$ & $10 \mathrm{mg}$ & $13 \mathrm{mg}$ & Total \\
\hline $\begin{array}{l}\text { 1-OHP } \\
\text { (ng/g creatinine) }\end{array}$ & $58.16 \pm 49.48(n=46)$ & $62.28 \pm 70.58(n=74)$ & $63.51 \pm 68.75(n=79)$ & $74.88 \pm 73.68(n=74)$ & $66.85 \pm 70.91(n=227)$ \\
\hline $\begin{array}{l}\text { 3-OHBaA } \\
\text { (ng/g creatinine) }\end{array}$ & $10.98 \pm 4.39(n=2)$ & $11.01 \pm 13.30(n=23)$ & $9.17 \pm 12.89(n=13)$ & - & $10.35 \pm 13.00(n=36)$ \\
\hline $\begin{array}{l}\text { 3-OHBaP } \\
\text { (ng/g creatinine) }\end{array}$ & $1.30 \pm 0.20(n=2)$ & $2.83 \pm 1.78(n=9)$ & - & $6.00 \pm 4.44(n=39)$ & $5.41 \pm 4.21(n=48)$ \\
\hline
\end{tabular}

The results were expressed as mean \pm standard deviation.

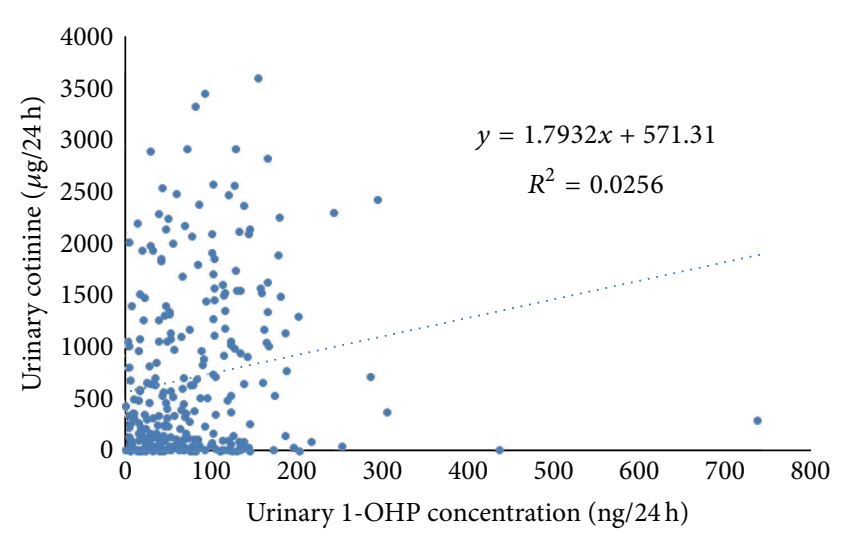

FIGURE 4: Correlation between urinary cotinine and 1-OHP.

respectively, which were much higher than those observed in this study. This might result from the fact that the subjects in our studies were exposed to extremely low levels of PAHs in the environment.

After creatinine correction, urinary 1-OHP concentrations in smokers were higher than those in nonsmokers, in agreement with previous reports $[41,44]$. In addition, urinary 1-OHP increased with the tar, $\mathrm{BaP}$, or pyrene in mainstream cigarette smoke. Two dose-response models relating $24 \mathrm{~h}$ urinary mean 1-OHP concentration and $\mathrm{BaP}$ yield in mainstream smoke under the ISO smoking regime and the Canadian intense machine smoking regime were established. The dose-response model between urinary 1-OHP and $\mathrm{BaP}$ yield under the ISO smoking regime $(93.00,148.20$, and $151.80 \mathrm{ng} / 15$ cigs $)$ was $y=-0.3322 x+157.18\left(R^{2}=0.0086\right.$, $n=227)$; under the Canadian intense machine smoking regime $(319.05,274.05$, and $337.95 \mathrm{ng} / 15$ cigs), BaP yield was

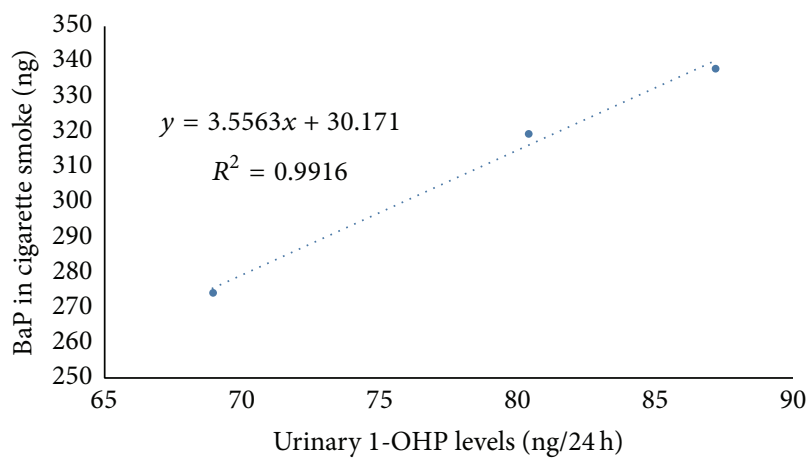

FIGURE 5: Correlation between urinary 1-OHP and cigarette smoke $\mathrm{BaP}$ under Canadian intense machine smoking regime.

strongly related to urinary 1-OHP $(y=3.5563 x+30.171$, $R^{2}=0.9916, n=227$, Figure 5).

\section{Conclusions}

A LC-APCI-MS/MS method for the simultaneous analysis of urinary 1-OHP, 3-OHBaP, and 3-OHBaA was developed and validated. The proposed method has good precision and accuracy, notably high sensitivity, and a relatively short chromatographic run time (12 $\mathrm{min})$. The method was successfully used to assess urinary 1-OHP, 3-OHBaP, and 3-OHBaA in nonsmokers and smokers with different tar yield cigarettes. After creatinine correction, urinary $1-\mathrm{OHP}$ and $3-\mathrm{OHBaP}$ increased with tar and $\mathrm{BaP}$ contents in cigarette smoke. Urinary 1-OHP levels were significantly correlated with $\mathrm{BaP}$ yield in cigarette smoke under the Canadian intense smoking condition. 


\section{Conflict of Interests}

The authors declare that there is no conflict of interests.

\section{Acknowledgment}

This study was supported by the National Nature Science Foundation of China (21105124, 21277174, 21347002).

\section{References}

[1] I. Yebra-Pimentel, E. Martínez-Carballo, J. Regueiro, and J. Simal-Gándara, "The potential of solvent-minimized extraction methods in the determination of polycyclic aromatic hydrocarbons in fish oils," Food Chemistry, vol. 139, no. 1-4, pp. 1036-1043, 2013.

[2] I. Yebra-Pimentel, R. Fernández-González, E. MartínezCarballo, and J. Simal-Gándara, "Optimization of purification processes to remove polycyclic aromatic hydrocarbons (PAHs) in polluted raw fish oils," Science of the Total Environment, vol. 470-471, pp. 917-924, 2014.

[3] L. Rey-Salgueiro, E. Martínez-Carballo, M. S. García-Falcón, C. González-Barreiro, and J. Simal-Gándara, "Occurrence of polycyclic aromatic hydrocarbons and their hydroxylated metabolites in infant foods," Food Chemistry, vol. 115, no. 3, pp. 814-819, 2009.

[4] R. Fernández-González, I. Yebra-Pimentel, E. MartínezCarballo, and J. Simal-Gándara, "Feed ingredients mainly contributing to polycyclic aromatic hydrocarbon and polychlorinated biphenyl residues," Polycyclic Aromatic Compounds, vol. 32, no. 2, pp. 280-295, 2012.

[5] I. Yebra-Pimentel, R. Fernández-González, E. Martínez Carballo, and J. Simal-Gándara, "Searching ingredients polluted by polycyclic aromatic hydrocarbons in feeds due to atmospheric or pyrolytic sources," Food Chemistry, vol. 135, no. 3, pp. 20432051, 2012.

[6] M. S. García-Falcón, M. Pérez-Lamela, and J. Simal-Gándara, "Comparison of strategies for extraction of high molecular weight polycyclic aromatic hydrocarbons from drinking waters," Journal of Agricultural and Food Chemistry, vol. 52, no. 23, pp. 6897-6903, 2004.

[7] WHO-IARC, IARC Monographs on the Evaluation of Carcinogenic Risks to Humans. Air Pollution, Part 1. Some Nonheterocyclic Polycyclic Aromatic Hydrocarbons and Some Related Industrial Exposures, vol. 92, WHO-IARC, Lyon, France, 2010.

[8] L. Rey-Salgueiro, X. Pontevedra-Pombal, M. Álvarez-Casas, E. Martínez-Carballo, M. S. García-Falcón, and J. Simal-Gándara, "Comparative performance of extraction strategies for polycyclic aromatic hydrocarbons in peats," Journal of Chromatography $A$, vol. 1216, no. 27, pp. 5235-5241, 2009.

[9] L. Rey-Salgueiro, E. Martínez-Carballo, M. S. García-Falcón, and J. Simal-Gándara, "Survey of polycyclic aromatic hydrocarbons in canned bivalves and investigation of their potential sources," Food Research International, vol. 42, no. 8, pp. 983-988, 2009.

[10] M. R. Pérez-Gregorio, M. S. García-Falcón, E. MartínezCarballo, and J. Simal-Gándara, "Removal of polycyclic aromatic hydrocarbons from organic solvents by ashes wastes," Journal of Hazardous Materials, vol. 178, no. 1-3, pp. 273-281, 2010.

[11] S. G. Carmella, M. Chen, S. Han et al., "Effects of smoking cessation on eight urinary tobacco carcinogen and toxicant biomarkers," Chemical Research in Toxicology, vol. 22, no. 4, pp. 734-741, 2009.

[12] A. Leroyer, F. Jeandel, A. Maitre et al., "1-Hydroxypyrene and 3hydroxybenzo[a]pyrene as biomarkers of exposure to $\mathrm{PAH}$ in various environmental exposure situations," Science of the Total Environment, vol. 408, no. 5, pp. 1166-1173, 2010.

[13] F. J. Jongeneelen, R. B. M. Anzion, and P. T. Henderson, "Determination of hydroxylated metabolites of polycyclic aromatic hydrocarbons in urine," Journal of Chromatography B: Biomedical Sciences and Applications, vol. 413, pp. 227-232, 1987.

[14] U. Heudorf and J. Angerer, "Urinary monohydroxylated phenanthrenes and hydroxypyrene-the effects of smoking habits and changes induced by smoking on monooxygenase-mediated metabolism," International Archives of Occupational and Environmental Health, vol. 74, no. 3, pp. 177-183, 2001.

[15] F. J. Jongeneelen, "Benchmark guideline for urinary 1-hydroxypyrene as biomarker of occupational exposure to polycyclic aromatic hydrocarbons," Annals of Occupational Hygiene, vol. 45 , no. 1, pp. 3-13, 2001.

[16] J. Gündel and J. Angerer, "High-performance liquid chromatographic method with fluorescence detection for the determination of 3-hydroxybenzo[a]pyrene and 3-hydroxybenz[a]anthracene in the urine of polycyclic aromatic hydrocarbon-exposed workers," Journal of Chromatography B: Biomedical Sciences and Applications, vol. 738, no. 1, pp. 47-55, 2000.

[17] Y. Huang, Y. Tian, Z. Zhang, and C. Peng, "A HILIC-MS/MS method for the simultaneous determination of seven organic acids in rat urine as biomarkers of exposure to realgar," Journal of Chromatography B, vol. 905, pp. 37-42, 2012.

[18] A. Toriba, T. Chetiyanukornkul, R. Kizu, and K. Hayakawa, "Quantification of 2-hydroxyfluorene in human urine by column-switching high performance liquid chromatography with fluorescence detection," Analyst, vol. 128, no. 6, pp. 605610, 2003.

[19] S. G. Carmella, K.-A. Le, and S. S. Hecht, "Improved method for determination of 1-hydroxypyrene in human urine," Cancer Epidemiology Biomarkers \& Prevention, vol. 13, no. 7, pp. 12611264, 2004.

[20] T. Chetiyanukornkul, A. Toriba, T. Kameda, N. Tang, and K. Hayakawa, "Simultaneous determination of urinary hydroxylated metabolites of naphthalene, fluorene, phenanthrene, fluoranthene and pyrene as multiple biomarkers of exposure to polycyclic aromatic hydrocarbons," Analytical and Bioanalytical Chemistry, vol. 386, no. 3, pp. 712-718, 2006.

[21] L. C. Romanoff, Z. Li, K. J. Young, N. C. Blakely III, D. G. Patterson Jr., and C. D. Sandau, "Automated solid-phase extraction method for measuring urinary polycyclic aromatic hydrocarbon metabolites in human biomonitoring using isotopedilution gas chromatography high-resolution mass spectrometry," Journal of Chromatography B: Analytical Technologies in the Biomedical and Life Sciences, vol. 835, no. 1-2, pp. 47-54, 2006.

[22] O. Mazéas and H. Budzinski, "Solid-phase extraction and purification for the quantification of polycyclic aromatic hydrocarbon metabolites in fish bile," Analytical and Bioanalytical Chemistry, vol. 383, no. 6, pp. 985-990, 2005.

[23] L. Campo, F. Rossella, and S. Fustinoni, "Development of a gas chromatography/mass spectrometry method to quantify several urinary monohydroxy metabolites of polycyclic aromatic hydrocarbons in occupationally exposed subjects," Journal of Chromatography B: Analytical Technologies in the Biomedical and Life Sciences, vol. 875, no. 2, pp. 531-540, 2008. 
[24] C. J. Smith, W. Huang, C. J. Walcott, W. Turner, J. Grainger, and D. G. Patterson Jr., "Quantification of monohydroxy-PAH metabolites in urine by solid-phase extraction with isotope dilution-GC-MS," Analytical and Bioanalytical Chemistry, vol. 372, no. 1, pp. 216-220, 2002.

[25] W. Lee, H. S. Shin, J. E. Hong, H. Pyo, and Y. Kim, "Studies on the analysis of benzo(a)pyrene and its metabolites in biological samples by using high performance liquid chromatograpy/fluorescence detection and gas chromatography/mass spectrometry," Bulletin of the Korean Chemical Society, vol. 24, no. 5, pp. 559-565, 2003.

[26] A. Holm, P. Molander, E. Lundanes, S. Øvrebø, and T. Greibrokk, "Fast and sensitive determination of urinary 1hydroxypyrene by packed capillary column switching liquid chromatography coupled to micro-electrospray time-of-flight mass spectrometry," Journal of Chromatography B: Analytical Technologies in the Biomedical and Life Sciences, vol. 794, no. 1, pp. 175-183, 2003.

[27] D. Pigini, A. M. Cialdella, P. Faranda, and G. Tranfo, "Comparison between external and internal standard calibration in the validation of an analytical method for 1-hydroxypyrene in human urine by high-performance liquid chromatography/tandem mass spectrometry," Rapid Communications in Mass Spectrometry, vol. 20, no. 6, pp. 1013-1018, 2006.

[28] T. R. van de Wiele, K. M. Peru, W. Verstraete, S. D. Siciliano, and J. V. Headley, "Liquid chromatography mass spectrometry analysis of PAH hydroxylates, formed in a simulator of the human gastrointestinal tract," Journal of Chromatography B: Analytical Technologies in the Biomedical and Life Sciences, vol. 806, no. 2, pp. 245-253, 2004.

[29] R. Fan, Y. Dong, W. Zhang et al., "Fast simultaneous determination of urinary 1-hydroxypyrene and 3-hydroxybenzo[a]pyrene by liquid chromatography-tandem mass spectrometry," Journal of Chromatography B, vol. 836, no. 1-2, pp. 92-97, 2006.

[30] F. Onyemauwa, S. M. Rappaport, J. R. Sobus, D. Gajdošová, R. Wu, and S. Waidyanatha, "Using liquid chromatographytandem mass spectrometry to quantify monohydroxylated metabolites of polycyclic aromatic hydrocarbons in urine," Journal of Chromatography B: Analytical Technologies in the Biomedical and Life Sciences, vol. 877, no. 11-12, pp. 1117-1125, 2009.

[31] R. Fan, D. Wang, R. Ramage, and J. She, "Fast and simultaneous determination of urinary 8-hydroxy-2' - deoxyguanosine and ten monohydroxylated polycyclic aromatic hydrocarbons by liquid chromatography/tandem mass spectrometry," Chemical Research in Toxicology, vol. 25, no. 2, pp. 491-499, 2012.

[32] X. Xu, J. Zhang, L. Zhang, W. Liu, and C. P. Weisel, "Selective detection of monohydroxy metabolites of polycyclic aromatic hydrocarbons in urine using liquid chromatography/triple quadrupole tandem mass spectrometry," Rapid Communications in Mass Spectrometry, vol. 18, no. 19, pp. 2299-2308, 2004.

[33] FDA Drug Administration, FDA Guidance for Industry: Bioanalytical Method Validation, US Department of Health and Human Services, Food and Drug Administration, Center for Drug Evaluation and Research, Rockville, Md, USA, 2001.

[34] Z. Fan, F. Xie, Q. Xia, S. Wang, L. Ding, and H. Liu, "Simultaneous determination of nicotine and its nine metabolites in human urine by LC-MS-MS," Chromatographia, vol. 68, no. 78, pp. 623-627, 2008.

[35] H. Hou, W. Xiong, X. Zhang, D. Song, G. Tang, and Q. Hu, "LCMS-MS measurements of urinary creatinine and the application of creatinine normalization technique on cotinine in smokers'
24 hour urine," Journal of Analytical Methods in Chemistry, vol. 2012, Article ID 245415, 8 pages, 2012.

[36] CORESTA, "Determination of benzo[a]pyrene in cigarette mainstream smoke-gas chromatography-mass spectrometry method," Recommended Methods 58, 2004.

[37] ISO3308, Routine Analytical Cigarette-Smoking Machine-Definitions and Standard Conditions, International Organization for Standardization, Geneva, Switzerland, 2000.

[38] S. S. Waikar, V. S. Sabbisetti, and J. V. Bonventre, "Normalization of urinary biomarkers to creatinine during changes in glomerular filtration rate," Kidney International, vol. 78, no. 5, pp. 486494, 2010.

[39] Y. S. Ding, D. L. Ashley, and C. H. Watson, "Determination of 10 carcinogenic polycyclic aromatic hydrocarbons in mainstream cigarette smoke," Journal of Agricultural and Food Chemistry, vol. 55, no. 15, pp. 5966-5973, 2007.

[40] Y. Xia, Y. Han, P. Zhu et al., "Relation between urinary metabolites of polycyclic aromatic hydrocarbons and human semen quality," Environmental Science and Technology, vol. 43, no. 12, pp. 4567-4573, 2009.

[41] M. Lafontaine, C. Champmartin, P. Simon, P. Delsaut, and C. Funck-Brentano, "3-Hydroxybenzo[a]pyrene in the urine of smokers and non-smokers," Toxicology Letters, vol. 162, no. 23, pp. 181-185, 2006.

[42] B. Veyrand, V. Sirot, S. Durand et al., "Human dietary exposure to polycyclic aromatic hydrocarbons: results of the second French Total Diet Study," Environment International, vol. 54, pp. 11-17, 2013.

[43] J. Grainger, W. Huang, D. G. Patterson Jr. et al., "Reference range levels of polycyclic aromatic hydrocarbons in the US population by measurement of urinary monohydroxy metabolites," Environmental Research, vol. 100, no. 3, pp. 394-423, 2006.

[44] A. Toriba, H. Nakamura, T. Chetiyanukornkul et al., "Method for determining monohydroxybenzo[a]pyrene isomers using column-switching high-performance liquid chromatography," Analytical Biochemistry, vol. 312, no. 1, pp. 14-22, 2003. 

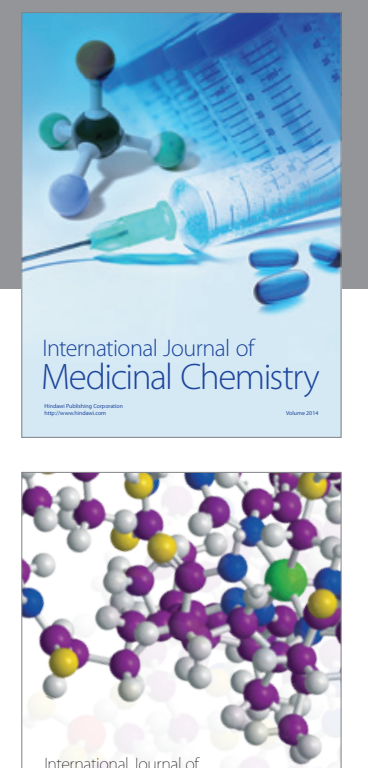

\section{Carbohydrate} Chemistry

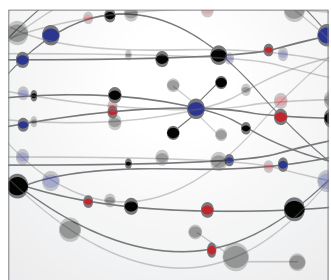

The Scientific World Journal
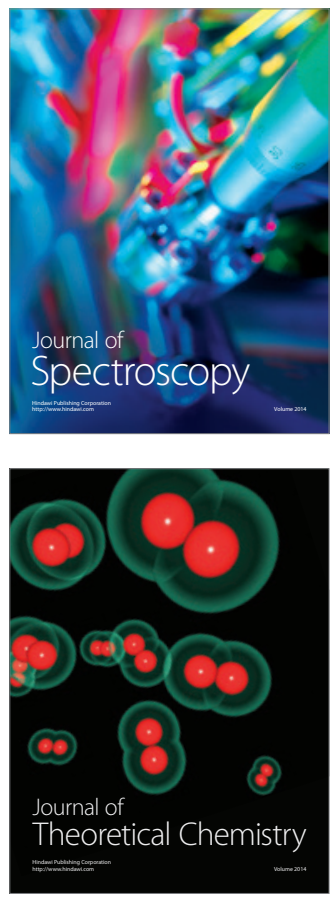
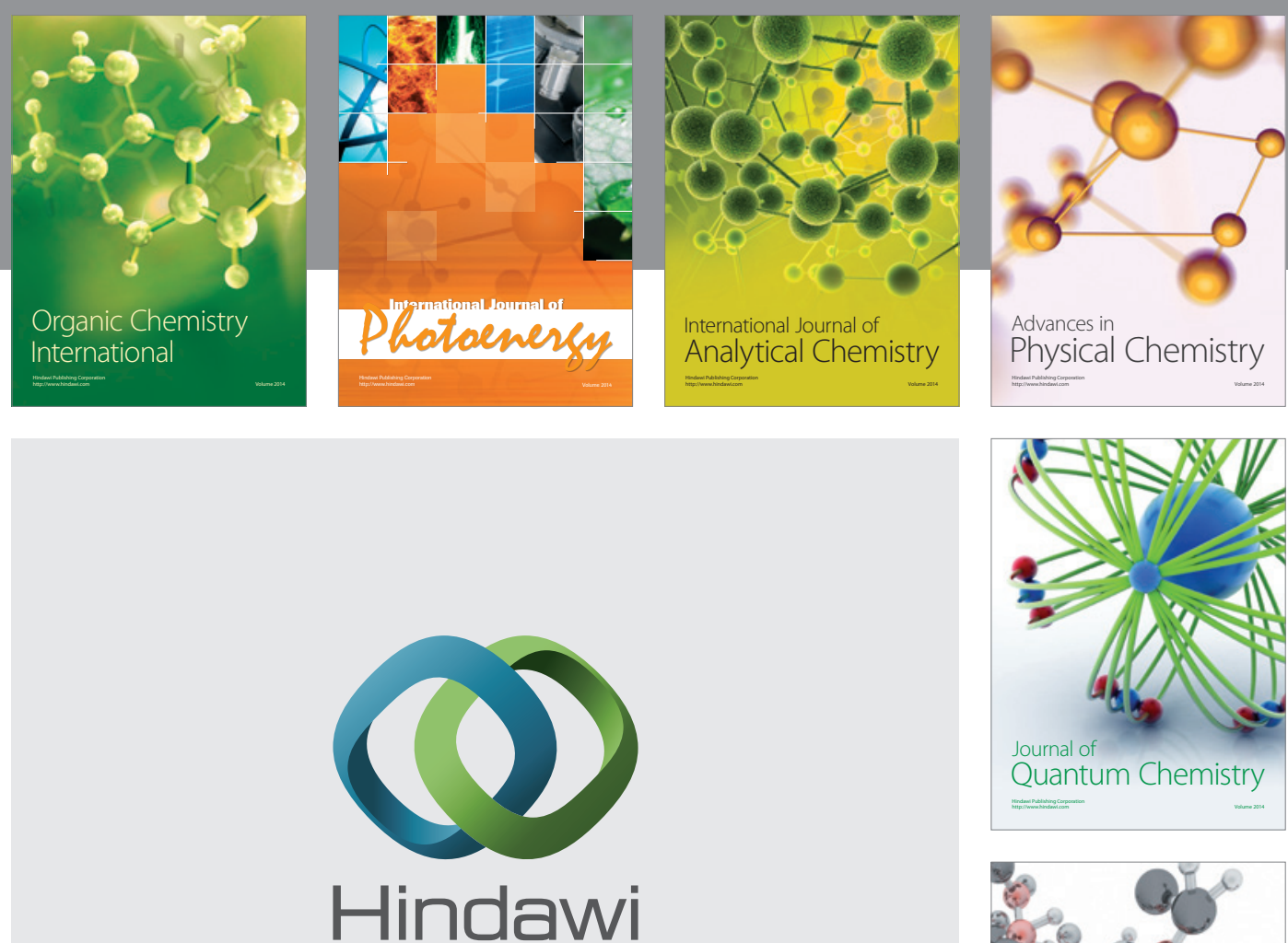

Submit your manuscripts at

http://www.hindawi.com

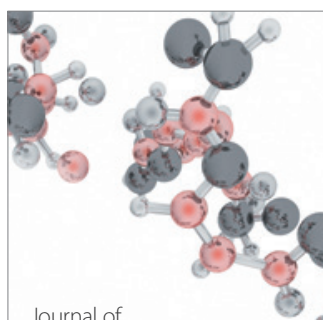

Analytical Methods

in Chemistry

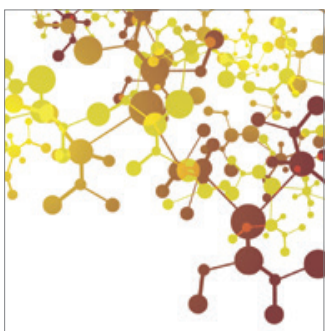

Journal of

Applied Chemistry

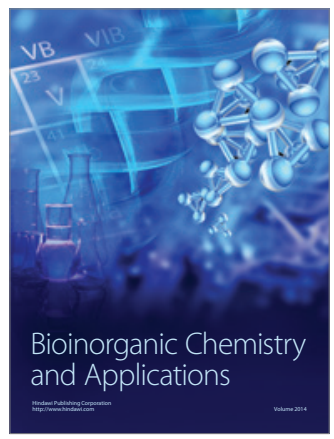

Inorganic Chemistry
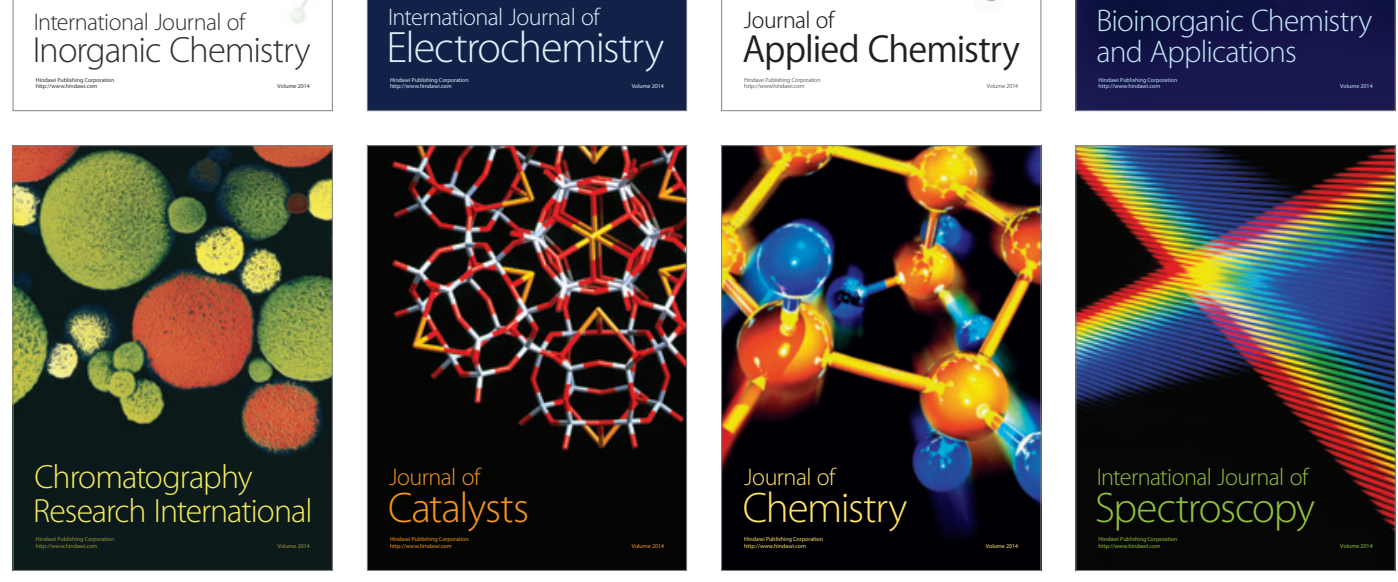